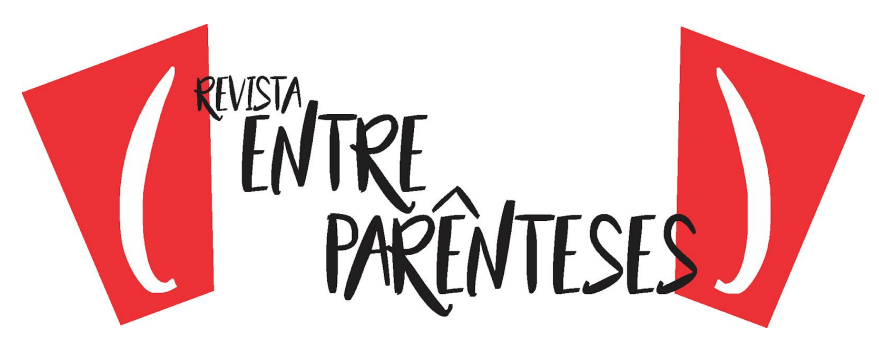

\title{
DE LA PALABRA ESCRITA A LA PALABRA CANTADA: LA VOZ DEL PUEBLO EN EL POEMA MUSICALIZADO
}

\author{
Cristian Javier Lopez ${ }^{1}$ \\ Universidade de Vigo \\ (cj_lopez2@hotmail.com) \\ Leila Shaí Del Pozo González² \\ Universidade Estadual do Oeste do Paraná \\ (leilashai@hotmail.com) \\ Marina Luisa Rohde ${ }^{3}$ \\ Universidade Estadual do Oeste do Paraná \\ (marinaluisar@gmail.com)
}

\begin{abstract}
Resumen: La confluencia entre la literatura, la historia y la música nos permite el estudio de los textos desde una perspectiva global que expande el mensaje propuesto en el cuerpo del objeto artístico. La importancia de los estudios interdisciplinares está en que éstos nos posibilitan la aproximación a un entendimiento más amplio de las expresiones artísticas que los sujetos sociales realizaron para dejar registro de sus voces en la historia. Este trabajo busca exponer algunas consideraciones sobre la relación literario-histórico-musical basadas en un poema de la escritora y crítica literaria uruguaya, Idea Vilariño. La mencionada poeta presentó en su obra numerosas producciones cuya temática explora la crítica social y en las que se demuestra la voz de una mujer comprometida con los problemas de su sociedad y la preocupación ante la desigualdad. Cabe destacar, además, que esas producciones líricas desde su origen estuvieron pensadas para ser musicalizadas y cantadas, lo que nos permite entender la importancia de la confluencia interartística que la escritora explora en su obra lírica. Además, este trabajo busca contribuir con los estudios sobre las obras de autoras latinoamericanas con el objeto dar visibilidad a las producciones de literatura escrita por mujeres en el continente.
\end{abstract}

Palabras clave: Idea Vilariño; Literatura e Historia; Lírica latinoamericana; Relaciones interartísticas; Literatura y Música.

\section{DA PALAVRA ESCRITA À PALAVRA CANTADA: A VOZ DO POVO NO POEMA MUSICALIZADO}

Resumo: A confluência entre literatura, história e música permite o estudo dos textos desde uma perspectiva global que expande a mensagem proposta no corpo do objeto artístico. A importância dos estudos interdisciplinares está em que estes possibilitam aproximar um entendimento mais amplo das expressões artísticas que os sujeitos sociais realizaram para deixar registradas suas vozes na história. Este trabalho busca expor algumas considerações sobre a relação literário-histórico-musical

\footnotetext{
1 Doctorando del Programa de Posgrado Interuniversitario en Estudios Literarios de la Universidade de Vigo, Vigo/España. Máster en Teatro y Artes escénicas, área de estudios literarios, por la Universidade de Vigo.

${ }^{2}$ Estudiante en el programa de Doctorado en Letras de la Universidad Estatal del Oeste del Paraná UNIOESTE, Cascavel/PR, Brasil. Máster en Letras, área de lenguaje y sociedad, por la UNIOESTE.

${ }^{3}$ Estudiante en el programa de Doctorado en Letras de la Universidad Estatal del Oeste del Paraná UNIOESTE, Cascavel/PR, Brasil. Máster en Letras, área de lenguaje y sociedad, por la UNIOESTE
} 


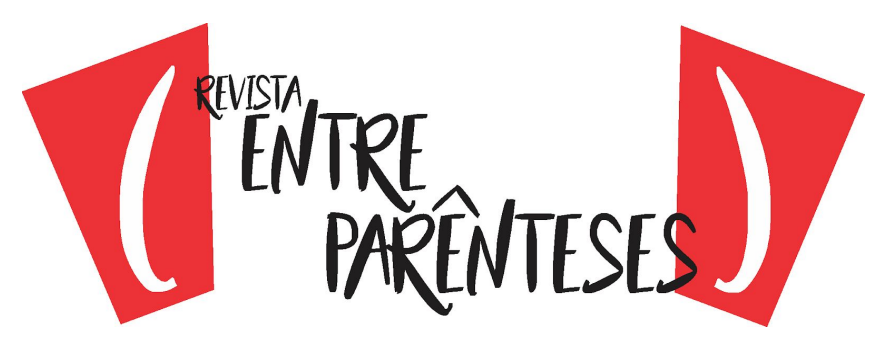

com base num poema da escritora e crítica literária uruguaia, Idea Vilariño. A referida poeta apresentou na sua obra inumeráveis produções cuja temática explora a crítica social e nas quais se mostra a voz de uma mulher compromissada com os problemas da sua sociedade e a preocupação diante a desigualdade. Cabe destacar, também, que essas produções líricas já desde sua origem foram planejadas para serem musicalizadas e cantadas, o qual permite entender a importância da confluência inter-artística que a escritora explora em sua obra lírica. Além do mais, este estudo busca contribuir com os estudos sobre as obras de autoras latino-americanas com o objetivo de dar visibilidade às produções de literatura escrita por mulheres no continente.

Palavras-chave: Idea Vilariño; Literatura e História; Lírica latino-americana; Relações interartísticas; Literatura e Música.

\title{
FROM THE WRITTEN WORD TO THE SINGING WORD: THE PEOPLE'S VOICE IN THE MUSICALIZED POEM
}

\begin{abstract}
The confluence between Literature, History and Music allows the study of texts from a global perspective of the expanded message proposed in the body of the artistic object. The importance of interdisciplinary studies lies in the possibility to approach to a broader understanding of artistic expressions of social subjects so as to register their voices in History. This paper offers some considerations on literary-historical-musical relations based on a poem by the Uruguayan author and literary critic, Idea Vilariño. The poet's composition approaches in several works the subject matter of social criticism. The aforementioned writer shows the voice of a woman compromised with social problems and inequality issues in her society. It is worth highlighting that her lyrical production was planned from the beginning to be musicalized and sung. This detail allows us to understand the importance of the interartistic confluence explored by the writer in her lyrical work. Furthermore, the paper intends to contribute to the studies related to female Latin-American authors to enhance visibility to the Literary work written by women on that continent.
\end{abstract}

Keywords: Idea Vilariño; Literature and History; Latin-American lyric; Confluence between arts; Literature and Music.

\section{Introducción}

El arte literario nos presenta un vasto campo de actuación que nos posibilita el diálogo con otras ramas del saber, como la historia y la música, por ejemplo. Es claro que estos diálogos no se basan solamente en la descripción más o menos detallada de algunos hechos históricos en el cuerpo textual o, menos aún, en la simple transposición de la palabra escrita en otro soporte artístico como el que ofrece la música. Las relaciones que se establecen entre estas disciplinas conllevan a que el objeto derivado de ellas, mediante la conjunción, amplíe el mensaje que el autor intenta exponer. Como lectores en el momento del contacto con el texto artístico, literario-musical, conseguimos tener una visión más amplia de la obra y 


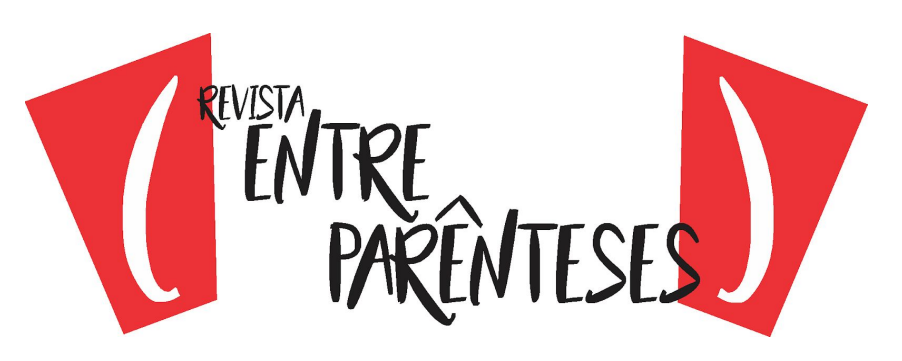

entender el mensaje propuesto desde una perspectiva general que nos pone informa sobre hecho histórico aunado con las artes de la palabra y del sonido, invitándonos a entender la obra artística de forma plena, en una unidad que, además, enriquece a cada una de las disciplinas que la componen.

Dentro del ámbito de la literatura, el género lírico nos muestra desde siempre una intensa conexión con la historia y la necesidad del sujeto social de plasmar los acontecimientos y sus vivencias. Además, gracias a la conexión con la música que este género presenta, se consigue la expansión del público receptor de la obra. Este hecho, el de la confluencia de la lírica con la música y la historia, es a primera vista algo común en las sociedades latinoamericanas, por ejemplo, si pensamos en aquellas obras más próximas al gran público y que tienen estrecha relación con la divulgación de una perspectiva de la historia como son los himnos nacionales de cada país, las canciones de guerra, la música de protesta, etc. Estas obras, que se vienen presentando desde hace mucho tiempo, debido a su amplia divulgación y conexión con la formación de las sociedades, llegaron a ser entendidas como productos literario-artísticos de una gran naturalidad, como si este hecho común, referente a la expresión de la historia por medio del arte de la palabra musicalizada, no pudiese aportar nuevas perspectivas de estudio e investigación. Es decir, la naturalización de la conexión que presentan aquellas obras cantadas que cuentan la historia quizás dejó de lado la importancia que estas obras pueden tener efectivamente para los contextos en los cuales se produjeron.

Las sociedades cambian a lo largo de la historia, por ende, las producciones artísticas elaboradas por éstas acompañarán dichos cambios y, por lo tanto, a pesar de que la conexión entre las disciplinas sea una constante, aquello que expresan y de la manera en que lo hacen siempre podrá aportar nuevas posibilidades de estudio. De este modo, el diálogo entre las disciplinas mencionadas, a pesar del lugar común que el sentido corriente pueda otorgar, permite que en la contemporaneidad observemos la continuación de la expresión de las sociedades, 


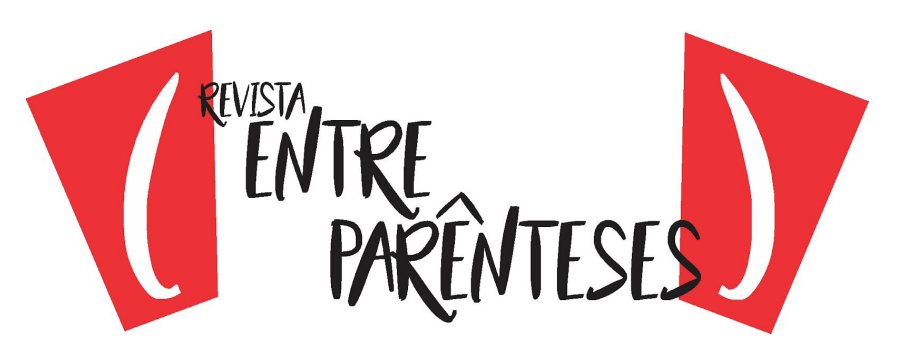

sus puntos de vista y la importancia de dejar para la posteridad la voz que deseaban o podían presentar por medio de la música.

En este sentido, son numerosos los poetas latinoamericanos que conscientes del poder de la palabra buscaron exponer su visión crítica del mundo, su incomodidad con la desigualdad y su voz frente a las imposiciones que el autoritarismo intentaba callar. Para este trabajo nos basamos en un poema/canción de la escritora y teórica uruguaya Idea Vilariño, quien dedica parte de su obra a la escritura de poemas que obtuvieron versiones musicales en las que ella explora el tema de la crítica social.

Además, consideramos importante destacar otro de los puntos en los que se basa nuestro trabajo que es el de la relevancia del estudio de la literatura escrita por mujeres en el espacio latinoamericano. Este hecho cobra notoriedad cuando pensamos en la desigualdad cuantitativa de las producciones de autoría femenina pertenecientes al canon literario, que en su mayoría se constituye por escritores.

Esperamos, de esta manera, exponer la importancia de una voz femenina en la crítica social del continente, explorar la relación literario-histórico-musical y contribuir con los estudios dedicados a visibilizar las obras de literatura escrita por mujeres en el continente americano.

\section{La obra de Idea Vilariño y el contexto social de producción}

La producción lírica de Idea Vilariño es una construcción poética en la que prima el cuidado y exploración de la musicalidad de la lengua y la atención a los grupos simétricos derivados del ritmo en sus versos. La poeta uruguaya dedicó parte de su vida literaria al estudio y explicación metodológica de lo que ella denominó como la "masa sonora del poema", que busca entender mediante los sonidos vocálicos, la base que sustenta a la obra lírica, que es un hecho sonoro por naturaleza, según la autora. Estamos, por lo tanto, frente a una mujer escritora y 


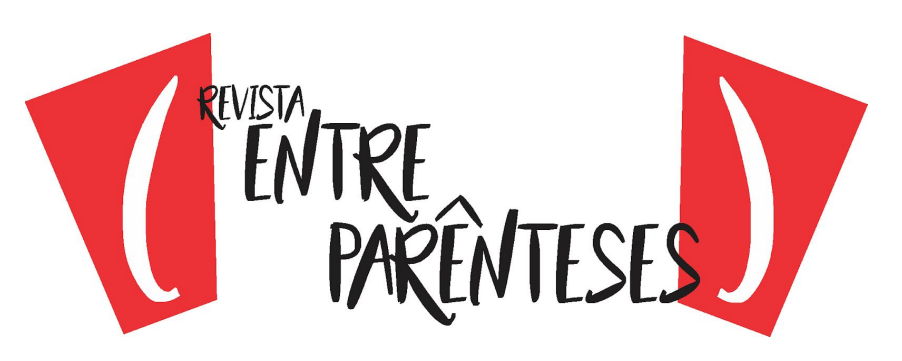

teórica del Cono Sur que además de producir obras en el área de la lírica también se destacó en el ámbito de la teoría y crítica literaria, además de realizar trabajos en el área de la traducción.

Lo mencionado anteriormente nos demuestra la importancia de esta mujer en el espacio de las letras de América Latina, un espacio que históricamente se construyó como un lugar casi de total exclusividad para los hombres. Las consideraciones expuestas nos abren el camino para el conocimiento de la obra de la autora desde dos perspectivas. Por un lado, el cuidado con el estudio y construcción del poema desde su estructura que nos invita a descubrir una escritora que aplicaba en su quehacer poético aquello que proponía en su trabajo teórico. Por otro lado, el amplio campo de actuación en el que transitó nos permite observar el lugar que se forjó como escritora en un continente, como comentamos antes, cuyo ámbito letrado tuvo desde sus inicios una preponderancia masculina. Esta última consideración le otorga a la autora en cuestión destaque en comparación a otras escritoras contemporáneas suyas que desarrollaron, por diversas razones de índole cultural, económica y política, su trabajo en el campo de la lírica, únicamente.

Entre los numerosos temas que la autora explora en su poética se destacan algunos como el paso del tiempo, el existencialismo, la musicalidad y la crítica social, entre otros. Sobre el último tema, la poeta produjo obras en las que se demuestra su compromiso social a nivel mundial, con poemas que reflexionan sobre los problemas relacionados a la guerra; a nivel continental, explorando una visión anti-imperialista y a favor de las naciones del continente americano; y a nivel nacional, cuyas obras se basan en los conflictos sociales advenidos del autoritarismo y la guerrilla en su país.

El poema/canción seleccionado para este trabajo es "Los Orientales" y fue creado en un período conturbado de Uruguay, entre las décadas de 1960 e inicios de 1970. La obra pertenece a la publicación Canciones (1993), un pequeño libro que 


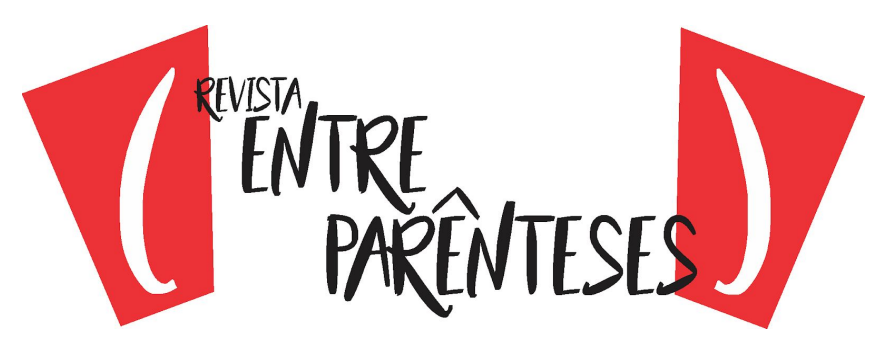

recoge los poemas que ganaron versiones musicales y aquellos que la propia autora escribió para ser cantados.

Con respecto al contexto de producción de la obra observamos una época marcada por grandes problemas a nivel social tanto mundial como nacional. Los autores latinoamericanos, lejos de mostrarse ajenos a ellos, se expresaron en producciones que buscaban que la sociedad reflexionara sobre lo que estaba ocurriendo. Sobre los problemas vividos en aquella década, la estudiosa Guerra comenta que

\begin{abstract}
Durante la década de 1960, en diversos puntos geográficos ocurrieron importantes enfrentamientos que pusieron de manifiesto las voces disidentes de estudiantes, intelectuales y trabajadores con respecto a la organización social y los derechos de los ciudadanos. La multitudinaria concentración política en Washington, bajo el liderazgo de Martin Luther King (marzo de 1963), la toma de la Universidad de Columbia (abril de 1968), las barricadas en París (mayo de 1968) y las manifestaciones en Tlatelolco (octubre de 1968) fueron en cada caso los hitos del descontento nacional, catalizado por la violencia de la guerra en Vietnam que produjo reacciones pacifistas. (GUERRA, 2008, p. 23).
\end{abstract}

Podemos encontrar en la producción de Idea Vilariño numerosos poemas en los que se expresa la voz de la poeta latinoamericana preocupada con los problemas que ocurren a nivel global ${ }^{4}$ y nacional. En lo que respecta a este último espacio, el nacional, podemos observar a un país dividido ${ }^{5}$ entre las acciones consideradas autoritarias por parte del gobierno nacional y la creciente guerrilla. En la década de 1960, de acuerdo con el estudioso Nahum (2013) se observa como

\footnotetext{
${ }^{4}$ Para conocer más sobre los poemas de crítica social se sugiere la lectura de la segunda parte del poemario Pobre Mundo en el que la escritora demuestra su compromiso social con el continente.

${ }^{5}$ De acuerdo a lo registrado por Nahum (2013, p. 271): "El Parlamento se encontró en el dilema de enfrentar la violencia tupamara sin alentar el autoritarismo del Ejecutivo, y vaciló en su actuación: algunos diputados y senadores se arriesgaron a defender sus fueros, pero otros entendieron que enfrentar al Ejecutivo era ayudar a la guerrilla, y ello reflejó las dificultades que partidos y fracciones tenían para desarrollar una actuación coherente frente a ambos problemas".
} 


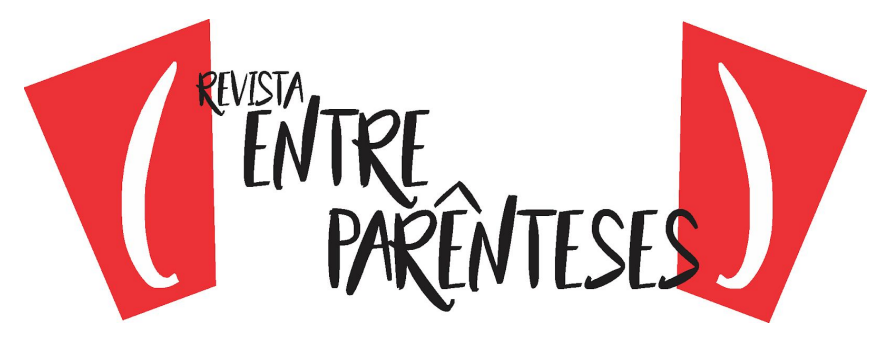

[...] uno de los motivos de los avances autoritarios del Poder Ejecutivo: los partidos políticos estaban fragmentados y también ellos sometidos a las interrogantes del desenlace de una creciente movilización sindical y estudiantil y, sobre todo, de la acción armada de la guerrilla. (NAHUM, 2013, p. 270-271)

Además, se debe considerar junto con la fragmentación política del país también el caos social que trajeron una serie de asesinatos en las manifestaciones populares y que fueron gradualmente afectando la libertad del pueblo y dando entrada, posteriormente, a lo que sería el período de dictadura que sufrió Uruguay entre 1973 a 1984. En este sentido, Nahum comenta que

La aceptación resignada de la violencia puede visualizarse con un ejemplo: cuando murió el primer estudiante (Líber Arce, 14 de agosto de 1968) víctima de la represión policial, la población montevideana, transida ante tal extremo de violencia, inédita en muchas décadas en el país, acompañó en gran número su velatorio y sepelio. Pero en setiembre murieron dos estudiantes más y en enero del 69 un obrero municipal, y en julio y septiembre del 71 otros dos estudiantes y en diciembre del 72 otro más, apagándose paulatinamente la reacción popular frente a cada caso. (NAHUM, 2013, p. 271).

Como puede observarse en las palabras del historiador, la sociedad uruguaya paulatinamente fue obligada a ceder a las imposiciones violentas del gobierno. Por lo tanto, es lógico encontrar en la literatura del país manifestaciones que denuncien lo que estaba pasando con la idea de dejar registrada una visión diferente de la que el poder político de ese momento sugería. La voz de una mujer en ese contexto se torna todavía más significativa debido al lugar que ocupaba la figura femenina en esas sociedades latinoamericanas. Para complementar lo expuesto por Nahum, el propio historiador cita un trecho de la obra Historia Uruguaya con la que se puede entender cómo gradualmente se dio paso a la posterior dictadura en el país: 


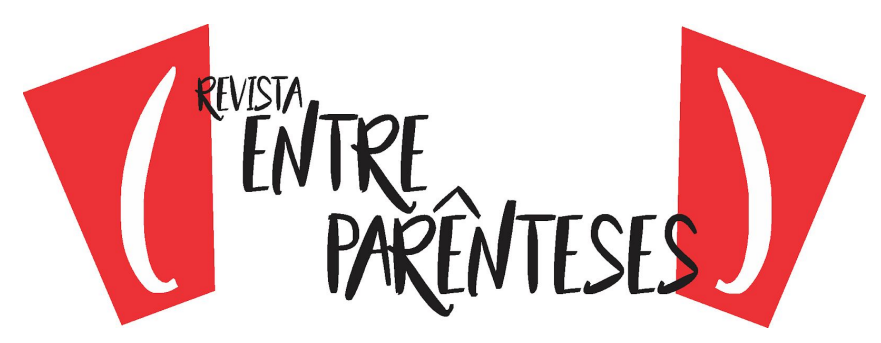

Se fue haciendo 'normal' que las distintas movilizaciones sociales fueran reprimidas con armas de fuego y que la pena por manifestar contra el Gobierno pudiera llegar a ser la muerte. Allí, en la lenta aceptación de tales hechos por la población, impotente para resistirlos y doblegada por la violencia, empezó a perderse la democracia. (HISTORIA URUGUAYA, t. 8, p. 63, apud NAHUM, 2013, p. 271).

De acuerdo a lo expuesto, podemos comprender, de modo general, el panorama que rodeaba a la escritora al momento de creación de sus poemas. Estamos frente a un escenario social marcado por la inestabilidad y la división que desde las altas esferas políticas, de acuerdo a lo registrado en la historiografía oficial, no supieron manejar. En este sentido, la obra seleccionada para este artículo busca destacar el espíritu de unidad nacional que el país estaba necesitando y, a la vez, se plantea como un incentivo para la lucha contra las imposiciones autoritarias del gobierno, demostrando la postura política de la autora.

\section{De la voz escrita a la voz cantada: el poema que cuenta la historia}

Al pensar en el continente americano nos viene como primera impresión la importancia de la tradición oral en sus sociedades. Ésta estuvo encargada de mantener vivas las costumbres de los pueblos y de transmitir a las generaciones venideras las memorias acumuladas. A partir de la colonización, el registro escrito se sobrepuso a la tradición oral, quedando éste como único medio valedero para la perpetuación de la cultura. Sin embargo, y a pesar del poder que impuso la escritura en las sociedades latinoamericanas, la oralidad siempre estuvo presente por medio de aquellas producciones cercanas al pueblo y a sus valores, como las canciones rituales, canciones de cuna, etc. a modo de resistencia cultural. En la contemporaneidad, observamos que la fusión de la tradición oral con el registro escrito es un aspecto característico de los autores latinoamericanos que se valieron de ello para exponer sus posiciones políticas. Éstos buscaron y buscan por medio de 


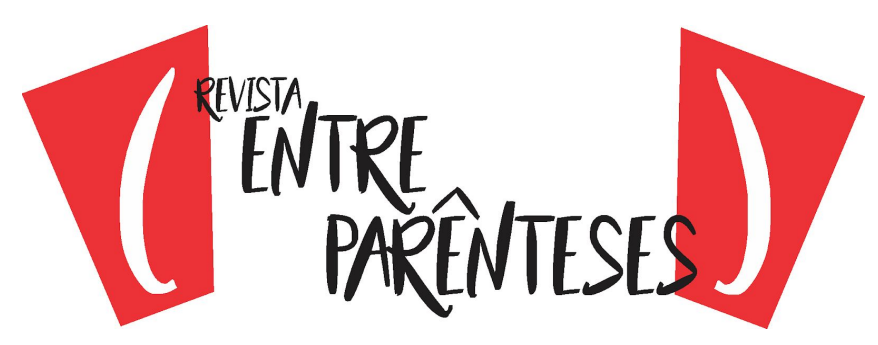

la expresión poética dar voz a sus perspectivas a favor de la sociedad oprimida y explotada por el poder hegemónico.

Los poemas de Idea Vilariño, una autora perteneciente al canon literario de su país y de importancia en las letras latinoamericanas, ganaron un nuevo cuerpo gracias a la musicalización dentro del ámbito popular. La propia autora compuso obras con el fin de ser ejecutadas en formas musicales como el tango o la vidalita. Por lo tanto, consideramos que ella, consciente de su papel como latinoamericana, sabía de la importancia de que su obra llegase a un público más amplio y que no quedara reducida solamente al espacio de la élite letrada, alcanzando de ese modo a un sector más amplio de los ciudadanos.

Como ejemplo de ello, es analizado en este trabajo el poema titulado "Los Orientales", una obra que se convirtió en un emblema de lucha para el pueblo uruguayo. Esta canción fue lanzada en la década de 1970 por el grupo de música popular Los Olimareños. A continuación presentamos la letra de la composición:

\section{Los Orientales}

De todas partes vienen, sangre y coraje, para salvar su suelo los orientales; vienen de las cuchillas, con lanza y sable, entre las hierbas brotan los orientales.

Salen de los poblados, del monte salen en cada esquina esperan los orientales.

Porque dejaron sus vidas, sus amigos y sus bienes, porque les es más querida la libertad que no tienen, porque es ajena la tierra y la libertad ajena y porque siempre los pueblos 


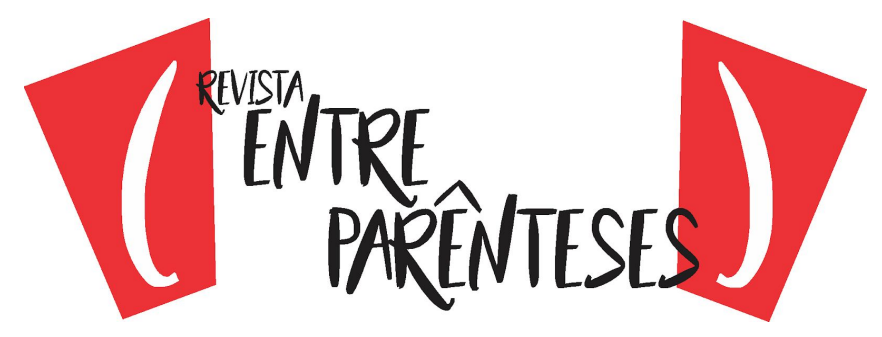

saben romper sus cadenas.

Eran diez, eran veinte, eran cincuenta, eran mil, eran miles, ya no se cuentan.

Rebeldes y valientes se van marchando, las cosas que más quieren abandonando.

Como un viento que arrasa van arrasando, como un agua que limpia vienen limpiando.

Porque dejaron sus vidas, etc. (VILARIÑO, 1993, p. 22; Arreglo de Los Olimareños, música de José L. Guerra).

El asunto propuesto en el poema expone un acontecimiento de gran importancia para la unificación del pueblo uruguayo. La canción se refiere a un hecho específico de la historia del país, concretamente, a las luchas por la independencia de Uruguay. El mencionado acontecimiento tuvo como protagonistas a un grupo de hombres que se alzaron en armas contra el Imperio brasileño y que fue denominado "los 33 orientales" . La obra lírica presenta una estructura sencilla a simple vista: dos estrofas de doce versos y un estribillo de ocho. La métrica utilizada alterna versos de siete y cinco sílabas en las estrofas y en el estribillo encontramos ocho sílabas poéticas. Sin embargo, como será expuesto más adelante, la estructura tiene una importancia relevante en el conjunto total de la obra.

\footnotetext{
6 De acuerdo a lo en: $<$ https://contenidos.ceibal.edu.uy/fichas educativas/ pdf/historia/rio-de-la-plata/054-la-cruzada-liberta dora.pdf>: "El 19 de abril de 1825, un grupo de hombres cruzó el río Uruguay en dos lanchones y desembarcó en las costas de Soriano. En la playa de La Agraciada juraron seguir hasta las últimas consecuencias. Su lema era 'Libertad o muerte' y llevaban la bandera con los colores de Artigas. Así comenzó un nuevo ciclo revolucionario. Instalaron un gobierno provisorio en Florida y en los años siguientes se produjo una guerra entre el Imperio del Brasil y las Provincias Unidas que culminó con la independencia del Uruguay".
} 


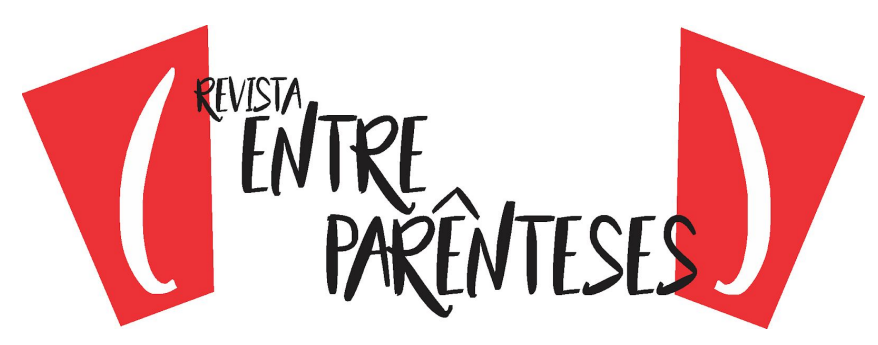

La canción forma parte del disco lanzado por Los Olimareños, en el año de 1970, cuyo título es "Cielo del 69" ${ }^{\prime 7}$. El contexto histórico de creación de la obra, como fue mencionado, nos refiere a una época de profunda crisis política y social en Uruguay $^{8}$, justamente antes de que se instalara la dictadura (1973-1984). La obra fue escrita en el conturbado año de la muerte del estudiante Jorge Salerno, a quien Idea Vilariño también dedicó el poema "La Isla".

Uno de los puntos interesantes que plantea esta composición, que como fue comentado en un primer momento aparenta una estructura sencilla, es que a nivel estructural/musical realiza una mezcla entre dos géneros significativos para el país y el continente. Las estrofas, de siete y cinco sílabas poéticas, están creadas con los metros utilizados para la composición musical denominada triunfo, que es una danza folklórica. Este ritmo popular se tornó característico en la época de las independencias latinoamericanas. El estribillo de la obra, a su vez, ganó en la composición musical el ritmo de una milonga, un género característico de la región rioplatense y que tiene gran conexión con las expresiones artísticas del país. Es decir, la composición poético-musical se presenta como una canción que explora el tema de la independencia del país, mediante la evocación de la figura emblemática de los 33 orientales. Este asunto explorado en la obra nos permite comprender de modo más significativo el tema del poema: la libertad y la soberanía del pueblo. Asimismo, tanto el tema como el asunto tratados en el poema ganan destaque gracias a la utilización de dos estilos musicales de gran peso en la historia del continente: el triunfo y la milonga. Por lo tanto, podemos considerar que estamos

\footnotetext{
${ }^{7}$ Según lo expuesto por el investigador Coriún Aharonian (2014: 277) la canción perteneció al disco Los Olimareños (1970). Cielo del 69. Vinilo. Uruguay: Orfeo. ULP 90543.

${ }^{8}$ De acuerdo con Nahum: "La novedad en el ámbito político uruguayo de la década de los 60 fue la aparición de grupos armados y sus repetidas manifestaciones de violencia. Estuvieron ambientadas en la dureza de la crisis económica y en la ineficacia de los partidos políticos, que fueron dejados de lado para emprender 'acciones' directas. Esto desvirtuó los principios democráticos y deterioró irreversiblemente por años el tradicional clima pacífico de la sociedad uruguaya, a lo que también contribuyó un Estado que quiso paliar su debilidad política con desbordes autoritarios". (NAHUM 2013, p. 272).

${ }^{9}$ La obra pertenece a la segunda parte del poemario "Pobre Mundo" (2012, p. 238)
} 


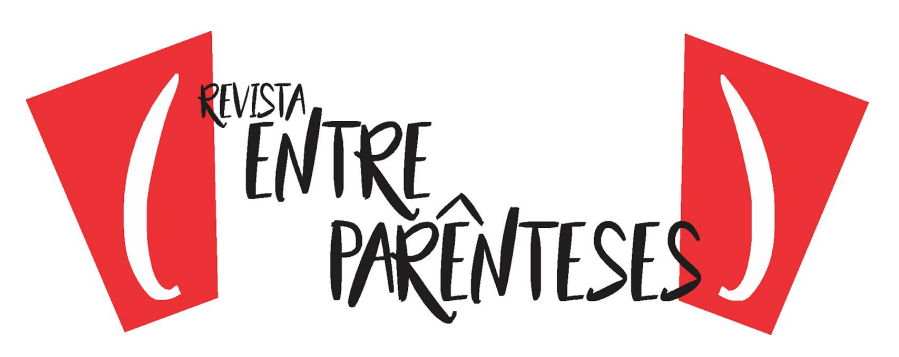

frente a una composición híbrida que, gracias a su conjunción literario-musical, explora de modo significativo elementos propios de la idiosincrasia latinoamericana. Estos recursos utilizados en la obra como un todo sirven para resignificar la historia de Uruguay y busca por medio de la evocación histórica de la figura de los orientales y el acto de liberación de Uruguay despertar en el pueblo la unificación necesaria para sobrepasar la situación de conflicto social en aquel momento de su producción.

La palabra cantada se expresa aquí como un elemento fundamental para la poeta. Es por medio de la conjunción con la música que la evocación de aquellos valores que la historia plasmó como símbolos de resistencia en el país gana un nuevo espíritu en la contemporaneidad. En este sentido, el discurso planteado por la poeta se respalda en la historia junto al hecho musical. De ese modo, podemos entender que el sentido de la obra poética amplía su alcance gracias a ésta conjunción. Asimismo, cabe mencionar el pensamiento del músico y estudioso Arnold Schoemberg, quien comenta:

¿Con qué finalidad se le pone música a un texto? [...] no existirían canciones, óperas ni oratorios si no se añadiese música que realzara la expresión de los textos. Además, ¿cómo se puede tener la seguridad de que esta música no ha de expresar algo, o mejor, que no ha de expresar algo provocado por el texto? Nadie puede evitar que las huellas digitales le identifiquen. Pero un manuscrito revela muchísimas cosas al grafólogo. (SCHOEMBERG, 1963, p. 278-279).

De acuerdo a lo expresado por Schoemberg, el elemento musical trabaja con lo propuesto por el texto, maximizando el discurso de la obra poética. El poema de Idea Vilariño en la versión musical aumenta su impacto al valerse de ritmos musicales de importancia cultural e histórica. Para complementar las reflexiones expuestas anteriormente sobre la composición de la poeta uruguaya y su posicionamiento político, el estudioso Coriún Aharonián comenta que: "en 1967 Idea se había integrado humildemente al Centro de la Canción Protesta (rebautizado posteriormente como Centro de la Canción Popular - también CCP - ante una 


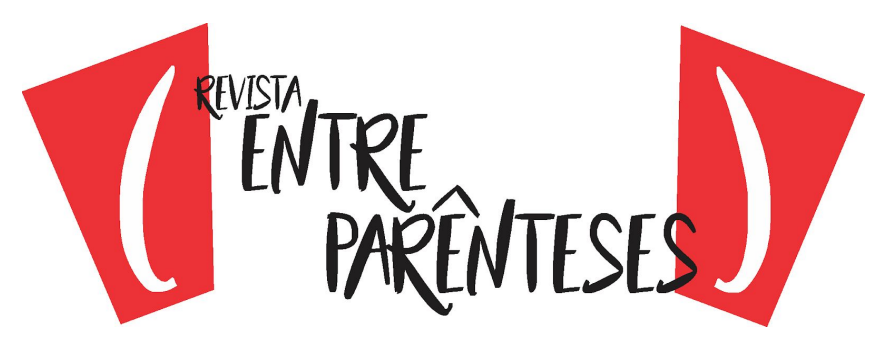

intentona represiva de las 'fuerzas del orden pachequista')" (2014, p. 263). De esta manera, se percibe la relación del compositor con la sociedad para la cual su obra es dirigida: una estrecha relación personal, plena de subjetividad. Para apoyar este argumento, Hormigos Ruiz (2008) expone, con respecto a la interacción entre el arte y la sociedad, que:

[...] la composición musical se verá afectada por la vinculación entre el estilo musical, la cultura del momento y la ideología. Para establecer un mejor entendimiento de la música deberemos, pues, fijarnos en los aspectos dinámicos de la cultura, ya que va a ser en la cultura donde encontraremos aspectos extramusicales que son imprescindibles para comprender el universo sonoro. La cultura es la que dota de una función específica al sonido, la que establece los lugares para la interpretación de la música, la que convierte una canción en un símbolo, la que marca actitudes y valores. (HORMIGOS RUIZ, 2008, p. 149).

La composición poético-musical se nutre de elementos exteriores que tienen sentido y/o serán complementados cuando sean considerados en el conjunto de la obra del artista. Idea Vilariño busca en los géneros musicales populares un espacio para transmitir lo sublime y hace de este arte una expresión posible de ser comprendida, apreciada y disfrutada por el gran público. Al considerar la importancia del alcance que la obra puede llegar a tener, observamos que la escritora fue consciente del valor de la música en sus obras como arte que amplía el público receptor.Este punto queda evidente en las palabras de presentación de la obra Canciones (1993) en las que la poeta comenta sobre su experiencia al escuchar sus poemas musicalizados:

Mi previa indiferencia por comunicar, mi larga vergüenza de publicar lo escrito, dejaron lugar a la alegría de escuchar esos textos tan bien musicalizados, tan bien cantados, que daban cuerpo a sentimientos e ideas que tantos compartían. La alegría de oírlos difundidos en un acto público, en las radios (bueno, en algunas, y nunca en T.V.), difundidos de manera casi anónima, porque nadie recordaba, por ejemplo, quién había escrito la letra de Los orientales, pero con qué compartida emoción, a la vuelta de Los Olimareños al país, lo cantó el Estadio entero, yo, nadie, entre ellos. Una limpia alegría porque 


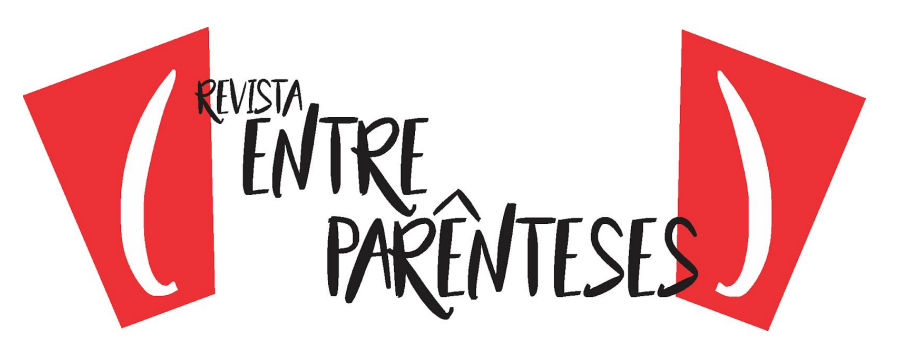

aquello era de todos, porque estábamos inmersos en aquella poderosa corriente del canto, e inmersos también en la adhesión de un público cálido, compañero y cómplice. (VILARIÑO, 1993, p. 5).

Como destaca la propia autora, la musicalización dio "cuerpo a sentimientos e ideas", es decir, aquello que estaba registrado en el papel/poema, para ser únicamente declamado, adquiere un nuevo ropaje, la canción, que encuentra acogida entre la multitud. La corporeidad del poema, la masa sonora, se ve concretada en el objeto musical.

En este sentido, vienen a colación las palabras del estudioso brasileño Massaud Moisés, quien comenta que "La literatura es la creación de una]'para-realidade', visto que o mundo ficcional não está 'acima' senão 'ao lado', paralelo da realidade ambiente, com ela realizando um permanente intercâmbio e nela se integrando inextricavelmente." (MOISÉS, 1993, p. 27). Podemos corroborar que para la poeta uruguaya esa comprensión no se da apenas a nivel abstracto, sino que se concretiza en su producción.

La musicalización de las obras de Idea Vilariño en el género popular resultó en la difusión del objeto artístico musical de manera masiva y bajo ese nuevo lenguaje se escuchó en "un acto público, en las radios", obteniendo así un nuevo público, como recuerda la poeta: "lo cantó el Estadio entero". Además, se destaca aquí un aspecto de democratización del nuevo producto lírico musical creado. Para la poeta su poema en su nueva forma de canción muestra otro producto, ya que "aquello era de todos". La conciencia de la importancia que se da al poema con su transposición a la música es clara en las palabras de Idea Vilariño quien en la presentación de la obra Canciones (1993) expresa: "Y así salían los textos a vivir con una vida más rica que la de los libros, a correr mundo con otros bríos, y a cumplir con la realidad tanto o más que aquellos." (VILARIÑO, 1993, p. 5).

El uso que la poeta hace de los elementos de carácter popular en la composición del poema-canción citado, le sirve para expresar una invitación al 


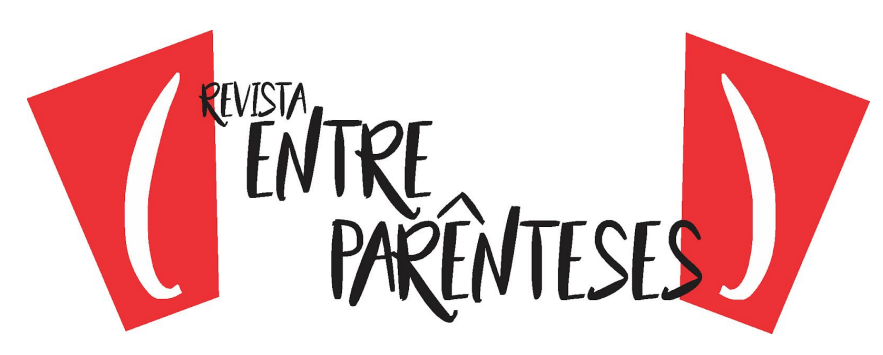

pueblo a la resistencia contra el sistema opresor del gobierno, se torna necesario cuando se busca alcanzar un vasto sector popular. En ese poema-canción la simplicidad es la marca fundamental que la poeta emplea y que permeará varias de sus producciones líricas.

\section{Conclusiones}

La lírica nos proporciona un espacio en el que pueden convergir diferentes campos del saber. El discurso que contiene el poema en su interior supone un diálogo con el lector a quien va dirigido y, como fue expuesto en este artículo, puede tener conexión con la historia. El arte de la palabra, en este sentido, posibilita la exploración de los hechos históricos desde otras perspectivas para exponer el mensaje del texto poético. Según Zumthor, "todo discurso es acción física y psíquicamente efectiva. De allí la riqueza de las tradiciones orales, que rechazan todo lo que rompe el ritmo de la voz viva [...] en la palabra se origina el poder del jefe y de la política, del campesino y de la semilla" (1987, p. 89).

Junto con el arte poético y la contribución del hecho registrado en la historia se encontró la colaboración de la música en el ejemplo analizado. Este arte, conforme fue corroborado, propuso un trabajo enriquecedor del discurso mediante el uso significativo de los géneros musicales populares. La contribución musical no se produjo únicamente por la transposición del texto poético, que explora un hecho histórico, a una melodía específica, sino que de modo concreto se utilizaron ritmos característicos del continente y de una gran importancia histórica.

El producto híbrido derivado de la conjunción poético-histórica-musical consiguió mostrar de modo concreto la posibilidad de trabajo e importancia de los estudios comparados al unir tres ramas del saber. Este tipo de producto no solamente es una agrupación de información sino que por el contrario es una mirada contemporánea sumamente interesante que los artistas latinoamericanos realizan 


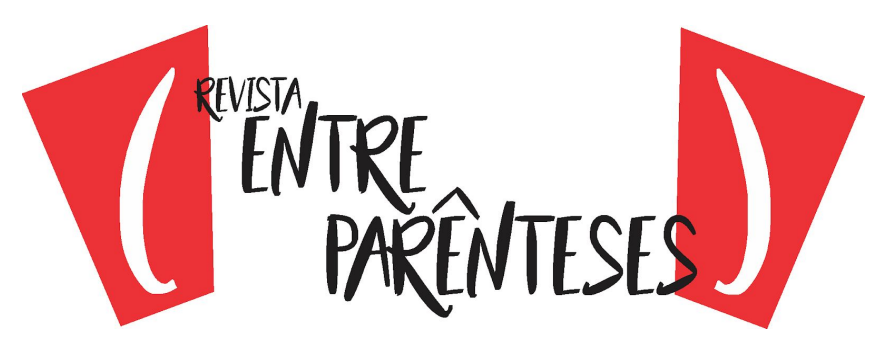

sobre su pasado frente a problemáticas actuales. Asimismo, el poema/canción se presenta como un producto democratizador que gracias a sus características estructurales y musicales permite que el poema consiga llegar a nuevos y diferentes espacios de la sociedad, proyectándose de una manera plural y significativa.

\section{Referencias}

AHARONIÁN, Coriún. El compromiso, la canción, la voz. Algunos apuntes en torno a Idea Vilariño. In: LARRE BORGES, A. I. (Ed.). Revista de la Biblioteca Nacional. Montevideo: Biblioteca Nacional, época 3, año 6, nº 9, pp 261-278, 2014.

GUERRA, Lucía. Mujer y escritura: fundamentos teóricos de la crítica feminista. Santiago-Chile: Editorial Cuarto Propio, 2008.

HORMIGOS RUIZ, Jaime. Música y sociedad-Análisis sociológico de la cultura musical de la posmodernidad. Madrid: Fundación Autor, 2008.

MOISÉS, Massaud. A Criação Literária - Poesia. São Paulo: Cultrix, 1993.

NAHUM, Benjamín. Manual de Historia del Uruguay, tomo I. Montevideo: Ediciones de la Banda Oriental, 2013.

SCHOEMBERG, Arnold. El estilo y la vida. Madrid: Ed. Taurus, 1963.

VILARIÑO, Idea. Canciones. Montevideo: La Banda Oriental, 1993.

ZUMTHOR, Paul. La letra y la Voz de la literatura medieval. Madrid: Ed. Cátedra, 1987.

Recebido em: 30/09/2019

Aceito em: 10/01/2020 